\title{
Elisabeth Gaucher, Robert le Diable. Histoire d'une légende
}

\section{Maria Colombo Timelli}

\section{(2) OpenEdition}

10 Journals

\section{Édition électronique}

URL : https://journals.openedition.org/studifrancesi/37186

DOI : 10.4000/studifrancesi.37186

ISSN : 2421-5856

Éditeur

Rosenberg \& Sellier

\section{Édition imprimée}

Date de publication : 15 décembre 2004

Pagination : 580

ISSN : 0039-2944

\section{Référence électronique}

Maria Colombo Timelli, « Elisabeth Gaucher, Robert le Diable. Histoire d"une légende », Studi Francesi [En ligne], 144 (XLVIII | III) | 2004, mis en ligne le 30 novembre 2015, consulté le 08 mai 2021. URL : http:// journals.openedition.org/studifrancesi/37186 ; DOI : https://doi.org/10.4000/studifrancesi.37186

Ce document a été généré automatiquement le 8 mai 2021.

\section{cc) (†) $\ominus$}

Studi Francesi è distribuita con Licenza Creative Commons Attribuzione - Non commerciale - Non opere derivate 4.0 Internazionale. 


\title{
Elisabeth Gaucher, Robert le Diable. Histoire d'une légende
}

\author{
Maria Colombo Timelli
}

\section{RÉFÉRENCE}

ELISABETH GAUCHER, Robert le Diable. Histoire d'une légende, Paris, Honoré Champion, 2003

(«Essais sur le Moyen Age», 29), 284 pp.

1 Ce beau livre suit l'histoire légendaire de Robert le Diable, récit de la rédemption d'un être involontairement diabolique, sur la longue durée, à partir de sa «naissance littéraire» au XIII ${ }^{\mathrm{e}}$ siècle jusqu'à l'époque moderne. Il s'agit d'un travail de synthèse dans lequel E.G. a repris le contenu de certains articles déjà publiés qu'elle a cependant su réorganiser dans un discours cohérent à l'aide de quelques études encore inédites.

2 La plus grande partie de l'ouvrage est consacrée aux origines de la légende et à ses multiples réécritures médiévales. L'histoire de Robert le Diable s'avère être à ses débuts, comme cela est fréquent dans le Moyen Age occidental, la reformulation chrétienne d'un substrat payen, qui demeure visible dans la symbolique des noms (Robert, forêt de Marabonde) et des métaux (fer, argent, or), ainsi que dans la présence de motifs liés à l'imaginaire folklorique (contes-types 314, «Petit jardinier aux cheveux d'or»; et M.219.1, le pacte avec le diable pour l'obtention d'un héritier) (Les origines, pp. 13-19).

3 Le récit a connu deux rédactions manuscrites en vers, l'une du XIII ${ }^{\mathrm{e}}$ siècle (ms. A), l'autre plus tardive (ms. B, remontant à la fin du XIV e-début du XV $\mathrm{XV}^{\mathrm{e}}$ siècle). E.G. parcourt les différentes traditions auxquelles puise l'auteur de cette première version (Le récit en vers $d u X^{X} I^{\mathrm{e}}$ siècle, pp. 21-97); elle dénombre ainsi des «motifs romanesques» (analogies évidentes avec le Merlin de Robert de Boron, mais aussi avec Perceval: naissance diabolique, rapport mère-fils, personnages récurrents - ermite, sénéchal, princesse -, thèmes de la folie, du sang), des «motifs féeriques» (le mystère des origines; l'ange, la fontaine, l'arbre) récupérés pour enjoliver le motif tout chrétien de 
la conversion exemplaire, des «motifs épiques» (la démesure, par laquelle le rapport avec Raoul de Cambrai est bien visible, la croisade, le conflit familial, sur lequel se greffe une intrigue amoureuse, la guerre, devenue cependant ici l'instrument d'une motivation individuelle), des «motifs hagiographiques» enfin (possession diabolique, intervention du Ciel, pénitence, utilisés pour vanter les mérites d'une conversion bien accomplie). Trouvent place dans ce même chapitre des considérations d'ordre plus général sur les repères historiques que l'on peut envisager pour contextualiser l'œuvre (cf. les motifs liés à la doctrine pénitentielle du XIII ${ }^{\mathrm{e}}$ siècle, mais aussi les ressemblances entre le protagoniste et le duc Robert ${ }^{\mathrm{er}}$ de Normandie, dit le Magnifique) et sur les enjeux épistémologiques mis en œuvre par l'auteur (questionnement sur la parole et le silence, de Dieu et de l'homme). Récit sans originalité réelle, ce qui, au Moyen Age, est une marque de qualité et non de pauvreté, Robert le Diable repose en somme, selon les mots de l'A., sur «l'agencement de traditions les plus diverses, sans distinction de genres» (p. 97).

Les réécritures médiévales font l'objet d'un chapitre à part (pp. 99-134). En fait, le récit traverse les siècles, jusqu'à l'avènement de l'imprimerie, dans un exemplum d'Etienne de Bourbon (moitié du XIII siècle, reproduit ici en annexe - version originale latine et traduction française -, pp. 184-188), la Grande Chronique de Normandie (vers 1350, annexe pp. 188-192), le Dit de Robert le Diable (première moitié du XIVe siècle), le trentetroisième Miracle de Notre-Dame par personnages (environ 1328-1350). C'est du Dit qu'est tirée la mise en prose imprimée à Lyon en 1496, par Pierre Mareschal et Barnabé Chaussart (voir la belle analyse proposée aux pp. 127-134).

5 Mais la légende connaît aussi une riche réception post-médiévale, dans la Bibliothèque Bleue, où elle est reçue dès 1620 , puis dans la réécriture de Jean Castilhon (1776) et dans la Nouvelle Bibliothèque Bleue (1843). Cette réception touche aussi d'autres domaines: la musique, avec l'opéra de Meyerbeer (livret d'Eugène Scribe, 1831: argument en annexe, pp. 209-213), la poésie (dans les ballades reproduites aux pp. 214-219), la pantomime (pp. 193-208), jusqu'au théâtre parodique (Guignol: pp. 220-263).

Robert le Diable a enfin inspiré enlumineurs et graveurs: E.G. reproduit 16 illustrations (miniatures des manuscrits médiévaux, bois unique de l'incunable lyonnais, gravures des éditions bleues), qu'elle commente dans le chapitre Texte et images (pp. 161-177).

7 La Bibliographie (pp. 265-275) est très riche et utilement organisée en sections: Editions et traductions, Etudes (récit du XIII , réécritures médiévales, adaptations postmédiévales, traductions étrangères; une petite partie est aussi consacrée au «prototype historique» de Robert le Diable). 